\title{
The marketing domino model
}

Received: 30th September, 2000

\section{Oeds J. Postma}

worked in the traditional database marketing field for several years. In this time he worked for Loyalty Management Netherlands (AirMiles) and VNU.

More recently the emphasis of his activities has shifted towards electronic dialogue. Currently he is active as a consulting partner for NoStamps e-Marketing. In addition to this, he regularly speaks and publishes on diverse database marketing issues.

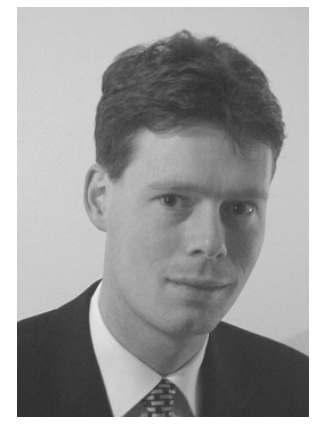

Abstract The Internet offers marketers many new ways to increase their effectiveness. The electronic nature of websites makes them natural tools for capturing data on individual customers. This does not, however, happen automatically.

This paper presents a framework that assists in the process of extracting data from the website. It shows where the company currently stands but also suggests logical ways to develop the website into an optimal data collection tool. The framework describes all phases and illustrates them with marketing questions and analyses that can help answer these questions.

\section{INTRODUCTION}

The evolution of the Internet can be classified in phases. This paper distinguishes three phases in the development of websites, inspired by the phases in e-commerce. ${ }^{1}$

In the first phase the main thing is to keep the website in the air and to ensure that all web features (like applications) function properly. The website performance (speed) is another important issue in this phase. Once the organisation is satisfied with this phase, the emphasis usually shifts towards design. In this second phase the company website is looked upon as if it were the company's business card. Eventually the design phase will evolve into the third phase when the emphasis will be more on relationship building. This is an important phase for database marketers. The building of relationships with individual customers will depend on marketers' skills. This phase is, therefore, the most interesting for database marketers, but probably also the most demanding phase for the organisation. These phases can be summarised as follows:

- Phase 1: technical phase. The IT department leads. The main focus is on making it happen. Customers can expect a stable and functional website

- Phase 2: design phase. In the second phase the designers become more important. The emphasis is more on the look of the website. The website has to be attractive and stimulating for customers

- Phase 3: database marketing phase. Database marketing will play an important role. The major goal is to build individual customer relationships. Therefore, it will be essential to collect the right data to support these one-to-one relationships. Customers can expect 
the company to interact with them and to learn from them.

Companies with a strong focus on database marketing will strive to have their websites in the third phase. For them the web can be a powerful tool to realise the full potential of their customer base. The central issue facing marketers will be to organise the website in such a way that it supports meaningful relationships with their customers or prospects. Keeping the relationships relevant requires extensive customer knowledge and, therefore, data. The electronic nature of the websites make them very interesting vehicles for generating these data. This paper provides a systematic manner to convert the website into a knowledge provider. This way the website will facilitate the online one-to-one marketing process.

\section{THE MODEL}

The domino model helps marketers organise the data side (back-end) of the website. The resulting datasets can address very diverse marketing issues. The model consists of separate, but interrelated, parts called modules. There is no standard way to move through these modules. Instead, there are several logical routes. The model can be used to distill an optimal data development route for the organisation. The paper begins by explaining the model and describing all modules. The model will be illustrated using marketing question examples. Finally, suitable data analysis methods will be shown.

\section{MODEL DIMENSIONS}

The essence of marketing is to match two entities: consumers and products. This fact is normally reflected in the organisational structure of the marketing department. Most department structures are based on one of these entities (customer or product). Traditionally, the focus was on products. Nowadays more departments are organised from the consumer point of view (customer segments).

The assumption underlying database marketing is that it is easier to match customers and products if there is more information on these combined entities. In other words, the more that is known about customers and the products they prefer, the better a company's marketing efforts can be. With the emergence of the Internet a new data source has become available. Since many customers browse on the Internet looking for products, these two entities constantly meet each other on-line. This makes many things measurable, but this does not happen automatically — it requires a well-organised background structure to the website. The remainder of this paper describes all situations and suggests how the background structure can be organised to achieve desired goals. The domino model uses these two marketing entities as model dimensions. The dimension describes how accurately visited items can be recognised (ie product information). The customer dimension describes how much is known about a website visitor (ie client information). (Since many companies do not yet sell directly through the web this paper will describe customers in more general terms as visitors and products or articles as items).

Within the visitor-item dimensions a number of categories can be distinguished.

\section{The item dimension}

'Items' refer to individual products, files or applications on the company website. 
Consider the example of a website containing a company's integral product line. Their products represent items here and are grouped together in product categories, each category having its own web page. Detailed information on individual products can be obtained by clicking on a particular product link within the category page. This example can be used to illustrate three different levels:

- no information is available on items: this is usually the starting point. It means that marketers cannot distinguish between different sections of the website. This happens when data are not captured for marketing purposes. In the above example it would mean marketers do not even have data on product categories since they cannot distinguish between separate web pages

- only information on item clusters available: this situation exists when marketers have information on grouped items but not on individual items. The sections people visit are known but not the exact items they look at. In terms of the example it means having information on web pages and thus on product clusters but not on individual products.

- information on separate items is available: this is the best a marketer can expect. It means that it is possible to distinguish between all individual items (products in the example) and therefore also on groups (web pages in the example).

\section{The visitor dimension}

A visitor is a person who visits the website. Visitors can be thought of as clients, but also as prospects or even partners. Within this dimension there are three levels:
- no information on visitors is available: in this case there is no information on visitors at all. This happens more often than most people think. In many cases companies only have Internet Protocol (IP) addresses of visits. But IP addresses do not necessarily represent individual people, since many people can share one address. In other cases addresses are generated dynamically, meaning that the same visitor will have a different IP address for every visit. Therefore visits cannot be related to each other

- only a non-extendable identification (id) is available: if the website places a cookie to remember a password, visitors can be recognised by their cookie-id as being the same on each subsequent visit. It is not known, however, who this person is, which makes it impossible to obtain explicit characteristics

- individual profile data are available: in this ideal situation marketers can recognise visitors but also know some of their characteristics. Interesting characteristics can be their e-mail address, postcode, gender, birth date and preferences. Requiring users to register via a login can capture this information very easily.

Unfortunately, borderlines between the categories are not always 100 per cent clear. In practice categories overlap. In addition to this there are gradations within the categories. The above division is, however, clear and reflects reality fairly. It will therefore be used in this paper.

\section{GRAPHICAL REPRESENTATION OF THE DOMINO MODEL}

If the consumer (visitor) and product (item) axes of both dimensions are combined a matrix results, as shown in 




Figure 1 Domino model overview

Figure 1. This matrix will serve to illustrate the development path.

Theoretically, it is possible to develop the ideal situation (cell C3) from scratch. In reality, a gradual development works better. If people or systems get overloaded with detailed data paralysis will arise. Also, the performance of systems will become a constraint. The huge amounts of data will place an enormous burden on the systems infrastructure. Therefore the advice is to start supplying marketers with high level data first. As soon as they are accustomed to the level of detail they will start to ask more detailed questions. At this point they can be provided with more detailed data. A famous Dutch example of how things can go wrong is that of the Albert Heijn bonus card.

In this example, Albert Heijn, Holland's biggest supermarket chain, with hardly any one-to-one marketing experience at all, decided to introduce their first loyalty card. At the same time, they implemented a marketing system containing all transactional data in minute detail for their marketing department. Marketers had no idea what to do with the highly detailed data. To make things worse, systems failed due to the huge amount of data and not even simple analyses could be run. Very soon after its introduction the system was not used at all.

The modules representing all possible situations (the matrix cells from Figure 1) are described below.

A1: anonymous visitors; general information on items. Many companies do not deliberately capture individual web data for marketing purposes, perhaps because they are still orientated to mass marketing. Even when counters are placed on the website, they only provide general traffic figures. Usually, there will still be web data since these data are generated automatically for technical reasons. These data should be found in the $\log$ files. From these $\log$ files general figures can be deduced. Some of these figures (page views, user sessions) can also be interesting for marketers. These basic figures can give marketers insight in the intensity of the website usage and the trends in this usage.

A2: anonymous visitors; item information on group level. A logical step is to collect item data on a group level (eg data on separate web pages). In order to do so it will generally be necessary to (re)structure the website's underlying file and directory structure. A possibility is to 
place related items into the same directories. When the browser requests items, the server writes the directory names into $\log$ files. From here the coded information can be extracted and analysed. The better the preparations have been done, the simpler the subsequent analyses will be. Reports created with these data provide an understanding of the popularity of different website sections. An alternative solution is to attach codes to transparent pixels and to include them in code of the desired pages. Nedstat uses this technique.

A3: anonymous visitors; item specific information. The last improvement is to $\log$ all items in detail. In order to keep things consistent and manageable it is recommended that marketers work with a clear coding syntax that identifies all items. This will improve the analysis. The information that can be retrieved in this situation gives marketers a good indication of the popularity of individual items and also of the sequence visitors use within sessions. A logical way of doing this is to place Java scripts on the website and have them write the codes (directly) into a database; the codes representing particular items. This method works very well with database driven-websites.

B1: visitors with id; general item information. If the web server is instructed to write cookies to client browsers, it is possible to get to know visitors a little better. Anonymous cookies (meaning that the person behind the cookie is unknown) make it possible to relate otherwise independent visits. This way, marketers can create indicators like retention. Armed with this information database marketers can investigate the loyalty of their visitors and the 'stickiness' of the website.

B2: visitors with id; item information on group level. If the detail of item information can also be increased things can be taken one step further. In addition to the points already mentioned, marketers can begin to look for time patterns and see if the behaviour of visitors changes over time. Is it that loyal visitors go to different sections on the site? Since individual consumers can be recognised, as well as some of their behaviour, the information available to marketers can increase in the course of time. The problem is that this information cannot be used to push communications, since no visitor profile data are available.

B3: visitors with id; item specific information. This information makes it possible to look for detailed patterns within the data. It can be seen how the behaviour of an individual relates to group behaviour. In this way suggestions can be made based on observations of the behaviour of a similar cluster. The classic example is Amazon's book recommendation engine.

C1: visitors with profile; general information on items. With individual customer data it is possible to start building profiles. The standard way of gathering these data is to require visitors to $\log$ on to the website, although it can also be done via cookies. (The latter method is, however, technically more complicated and give less reliable results.) Forms or surveys can be used to capture certain details about visitors. The captured information can be used to generate customer profiles. In this way, marketers gain better insights into their visitor types. It also makes it possible to enrich the data with external data. So, for example, if opt-in e-mail or physical addresses are collected the information can be used to push general communications.

C2: visitors with profile; grouped item information. Information on grouped items can be used to create visitor profiles per 
$0: 0$

Level of detail

General

Item

Individual item

Visitor

Id

Profile

\begin{tabular}{|l|l|l|}
\hline $\begin{array}{l}\text { How is our website } \\
\text { doing? }\end{array}$ & $\begin{array}{l}\text { How loyal are our } \\
\text { visitors? }\end{array}$ & $\begin{array}{l}\text { What are the typical } \\
\text { characteristics of our } \\
\text { visitors? }\end{array}$ \\
\hline $\begin{array}{l}\text { Wossion did we have? } \\
\text { Which parts of the } \\
\text { visitors did the } \\
\text { website attract? }\end{array}$ & $\begin{array}{l}\text { How is browsing } \\
\text { behaviour of visitors } \\
\text { changing over time? } \\
\text { Does it change if } \\
\text { users get to know the } \\
\text { site? }\end{array}$ & $\begin{array}{l}\text { What kinds of visitors } \\
\text { do different sections } \\
\text { draw? }\end{array}$ \\
\hline $\begin{array}{l}\text { How do visitors } \\
\text { browse within } \\
\text { sessions? }\end{array}$ & $\begin{array}{l}\text { In which other items } \\
\text { will visitors be } \\
\text { interested? }\end{array}$ & $\begin{array}{l}\text { Which visitors react } \\
\text { to what promotions? }\end{array}$ \\
\hline
\end{tabular}

One-to-one

Figure 2 Marketing questions

item group. Marketers can check, for instance, if older people visit other web pages than younger people and which pages they prefer. Outbound communications can be better segmented using visitor behaviour.

C3: visitors with profile; item specific information. This information gives marketers many opportunities. In theory, this situation makes it feasible to investigate who reacted to which banner/campaign; a true one-to-one marketing situation. This opens possibilities for remarketing but this requires precise (Java script) tracking. Another possibility is to see if certain groups behave differently on the website. It also makes it easier to label behavioural clusters.

\section{INTERESTING MARKETING QUESTIONS}

Figure 2 gives examples of questions that can be answered in all situations; the questions serve as illustrations only. All questions on a higher level of abstraction (towards the upper left) can also be answered by aggregating information from lower cells (towards the lower right).

\section{POSSIBLE ANALYTICAL METHODS}

All questions can be answered with the available data. Analyses will, however, be needed to extract the knowledge. The analyses help to turn data into knowledge. The matrix in Figure 3 shows examples of methods that can be used in different situations.

\section{GROWTH PATHS}

The domino model shows there can be several development routes. In essence, there are two main logical routes to improve the knowledge base: the consumer specific and the product specific routes (as shown in Figure 4).

The consumer specific route enhances knowledge by focusing on improving 


\begin{tabular}{|c|c|c|c|}
\hline Mass marketin & & Visitor & \\
\hline Level of detail & Anonymous & Id & Profile \\
\hline General & $\begin{array}{l}\text { General activity } \\
\text { reports }\end{array}$ & Retention analysis & Profile analysis \\
\hline Group & $\begin{array}{l}\text { Separate reports per } \\
\text { section }\end{array}$ & Time analysis & $\begin{array}{l}\text { Time analysis per } \\
\text { customer segment }\end{array}$ \\
\hline Individual item & Click path analysis & Basket analysis & Response analysis \\
\hline
\end{tabular}

Figure 3 Methods of analysis

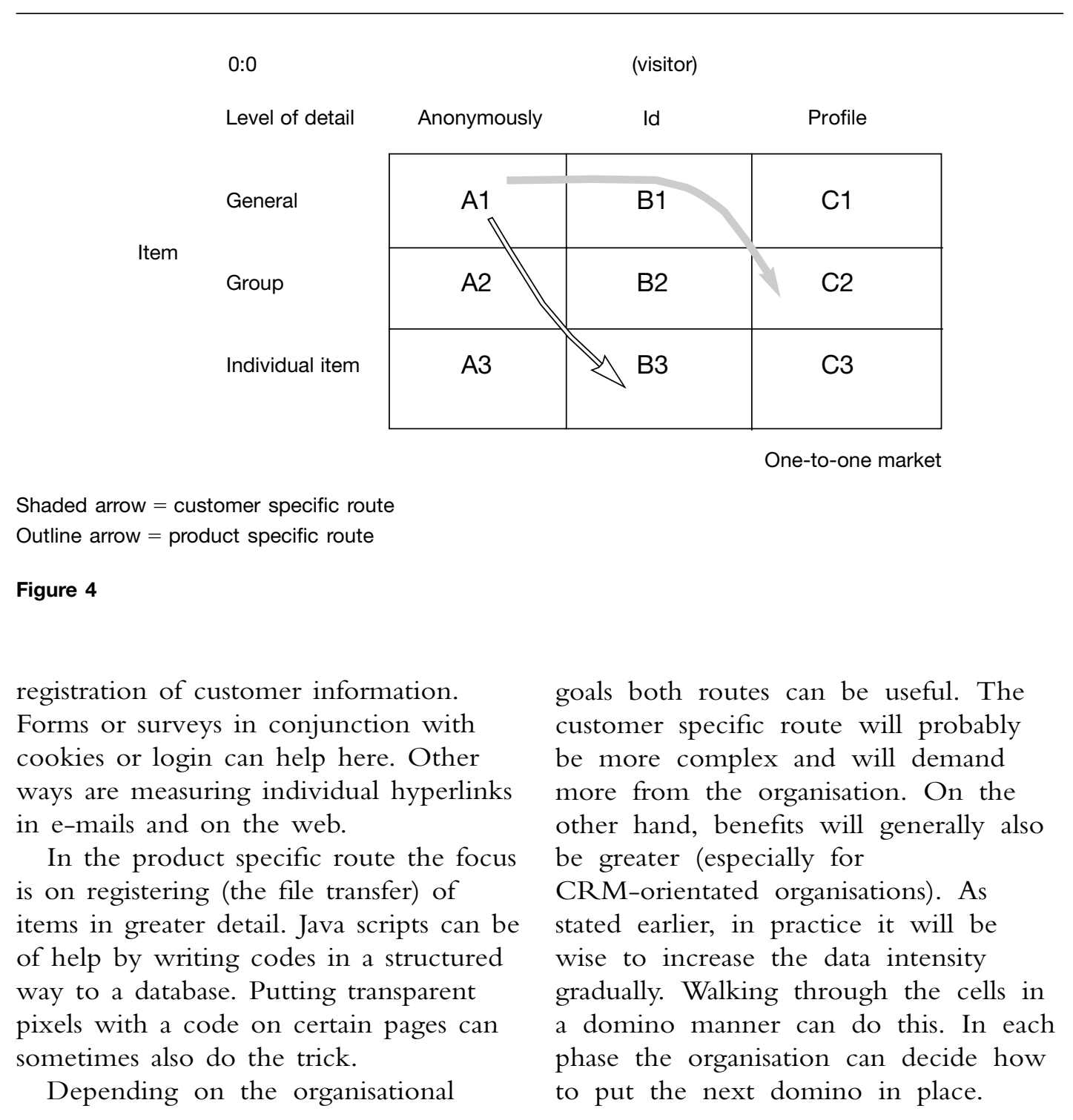




\section{CONCLUSIONS}

The domino model offers marketers a logical and flexible migration guide to turning their website into a source of individual customer data. The model classifies marketing questions and suggests analytical methods. It can also serve to show where the company's website stands 'database marketing wise' and in what direction it should be developed. In addition to this, it can help to improve communications between IT and marketing departments.

\section{References}

1 Broadvision white paper (1998)

'Business-to-business e-commerce: Finding the 80-20 solution'. 